\title{
Gastric Obstruction by Tricobezoar in Cat Associated with Lynxacarus radovskyi: a Case Report
}

\author{
Érico do Nascimento Arruda 1,2*, Marilene da Silva Marques 1,2, Paula Diniz Galera 3, Reginaldo \\ Pereira de Sousa Filho 4, Cynthia Levi Baratta Monteiro 4
}

\author{
${ }^{1}$ Faculdade Terra Nordeste, Ceará, CE, Brazil. \\ ${ }^{2}$ Vet World Clínica Veterinária, Ceará, CE, Brazil. \\ ${ }^{3}$ Faculdade de Agronomia e Medicina Veterinária, Universidade de Brasília, Brasília, DF, Brazil. \\ ${ }^{4}$ Universidade Estadual do Ceará, Ceará, CE, Brazil.
}

*Corresponding author: Érico do Nascimento Arruda. Rua Pereira Filgueiras, 1550 - Meireles, Fortaleza, $n^{0}$ District. Zip Code: 60160-194- Ceará, CE, Brazil.. Phone: +55 (85) 3104-5433. E-mail: ericoarruda@hotmail.com.

Research Ethics Committee Approval (if necessary): Not applied.

Received on: Apr 15, 2021. Accepted on: Apr 25, 2021. Available online: Apr 30, 2021.

\begin{abstract}
The presence of trichobezoar in cats is characterized by the accumulation of hair in the gastric cavity, which may be associated with the presence of dermatitis caused by the presence of the mite Lynxacarus radovskyi. In the present report, a clinical case of a feline patient with diagnostic and surgical diagnosis of the presence of a trichobezoar with the presence of Lynxacarus radovskyi in a skin scrape examination was described.
\end{abstract}

Keywords: Trichobezoar. Lynxacarus radovskyi. Surgery.

\section{Introduction}

According to the Federal Council of Veterinary Medicine (CFMV), the population of cats in Brazil is the second largest in the world and is close to equaling that of dogs. It is expected that in 2022 there will be about 40 million cats in Brazil. As a result, the number of professionals specializing in feline medicine has been increasing throughout the country [1].

Felines are frequently affected by stomach obstruction by foreign bodies, they can ingest bones, cartilage, feathers, inedible objects such as threads, threads, toys and hair. Ingestion can occur due to psychological disorders or skin diseases, such as: allergic dermatitis to flea bite (DAPP), atopy, dermatophytosis and mites. This intake can predispose the formation of bezoars [2-3].

The term "bezoar", generically, defines any formation found in the digestive tract formed, spontaneously, from the ingestion of various substances. Research indicates that the incidence of foreign bodies in the 
gastrointestinal tract reaches up to $48 \%$ in cats due to their habit of constantly licking and because they contain filiform papillae on their tongue, which work like sandpaper to remove dead hair from the surface [2-3].

In this way they end up ingesting some hair, when they are unable to move through the gastrointestinal tract, they cause trichobezoars or hair balls as it is popularly known [2-3].

It is common to see felines eliminate hairballs due to regurgitation or vomiting, which does not indicate any serious clinical situation, but proves their existence and, therefore, the need to do their control. Factors that increase the frequency of licking may predispose the formation of hair balls, and one of the most common causes of this increase is the presence of a mite called Lynxacarus [4-5].

Lynxacarus radovskyi is a mite related to feline skin diseases. They are chewing mites and move quickly through the animals' bodies. The most common clinical signs are pruritus, appearance of the "salt and pepper" dusted coat due to the visibility of the mites in the hair and flaking [6]. Alopecia can occur due to easy hair pulling, excessive dandruff and dermatitis. Due to the strong itching, in some cases, the animals start to lick excessively leading to gastrointestinal disturbances that may form a gastric obstruction and constipation by a hairball [6].
Most of the time, the ingested hairs are eliminated by the feces, but in some cases, the hairs can gather in the stomach, forming balls that can cause digestive problems and the need for a surgical procedure that, if not performed, can lead the animal to death [4].

In the present report, a clinical case of a feline patient with diagnostic and surgical diagnosis of the presence of a trichobezoar with the presence of Lynxacarus radovskyi in a skin scrape examination was described.

\section{Case report}

A 12-year-old female feline Persian (Figure 1A), weighing $3 \mathrm{~kg}$, castrated, domiciled and vaccinated, was assisted by a veterinary hospital in the city of Fortaleza / CE, with pictures of wounds on her back. , vomiting episodes, apathy, severe abdominal pain, without eating and urinating for three days. It was reported that the feline patient already had allergic flea bite dermatitis (DAAP) and had itchiness with excessive licking.

A complete physical examination of the feline patient was performed, followed by palpation of lymph nodes, capillary filling time, measurement of rectal temperature, cardiac and pulmonary auscultation, measurement of mucosal staining, inspection of hair and skin, and bladder and abdominal palpation.

On physical examination, moderate dehydration, pain in the 
stomach, bladder and strong halitosis were found. The mucous membranes were normal and the lymph nodes were not reactive. In addition, capillary filling time, cardiac and pulmonary auscultation and rectal temperature were within the normal range.

At the consultation, blood samples were collected for complete blood count, and biochemical tests for Alanine aminotransferase (ALT) and creatinine. Ultrasound and urinalysis by cystocentesis guided by ultrasound were requested.

Hematological and biochemical tests did not show significant changes. Ultrasonography shows gastric dilation and a lumen full of gas, making it impossible to see gastric contents due to the formation of an acoustic shadow (Figure 1B). The tutor did not perform the urinalysis by cystocentece as requested.

The diagnosis could not be defined only with complementary exams, so an exploratory laparotomy was requested, since the animal had a large gastric dilation and production of acoustic shadow consistent with the presence of bezoars. Until the surgical procedure, feline tramadol hydrochloride was prescribed at a dose of $4 \mathrm{mg} / \mathrm{kg}$ every 8 hours.

When performing the exploratory laparotomy, a large mass was observed inside the stomach (Figure 1C), suggesting a gastrotomy to remove the trichobezoar. During the surgical procedure, an incision was made in the hypovascular region in the ventral portion of the stomach between the major and minor curvatures.

After gastrotomy, the diagnosis of gastric obstruction by trichobezoar could be defined, since the mass found in the stomach cavity consisted of a large amount of hair (Figure 1D).

For the consolidation of gastric synthesis, two suture patterns were used: the first was simple separated, including the serous, muscular and submucosal layers; the second pattern was the simple continuous incorporating the serous and muscular layers. In both sutures, polyglactin absorbable thread was used.

After performing the surgical procedure and recovering the feline patient, when carrying out a physical examination to release the patient, small spots on the back coat with the appearance of salt and pepper were identified, accompanied by alopecia and fragile hair, so the suspicion was raised the presence of the Lynxacarus radovsky (Figure 1E).

A skin scraping was carried out that confirmed the presence of linxacariosis, thus consolidating the diagnosis of the cause of the trichobezoar since this case, since the presence of this mite can cause allergic dermatitis, and with this occur excessive licking thus explaining the cause of accumulation of hair in the gastric cavity of this animal. 
For the postoperative period, Profenid drops were prescribed as an anti-inflammatory at a dose of two drops every 24 hours for 3 days and Ranitidine suspension at a dose of 0.5 $\mathrm{ml}$ every 12 hours for 10 days for gastric lesions caused by trichobezoar. Cleaning the incision with physiological solution twice a day and applying Bepantol ointment for 7 days was indicated.
Revolution or Advocte was indicated to treat the lymphosis, applying to the back region, with repetition after 20 days. After 10 days of surgery, a better behavior of the feline patient was reported, presenting with good food and normal water intake, being discharged after removal of the surgical stitches.
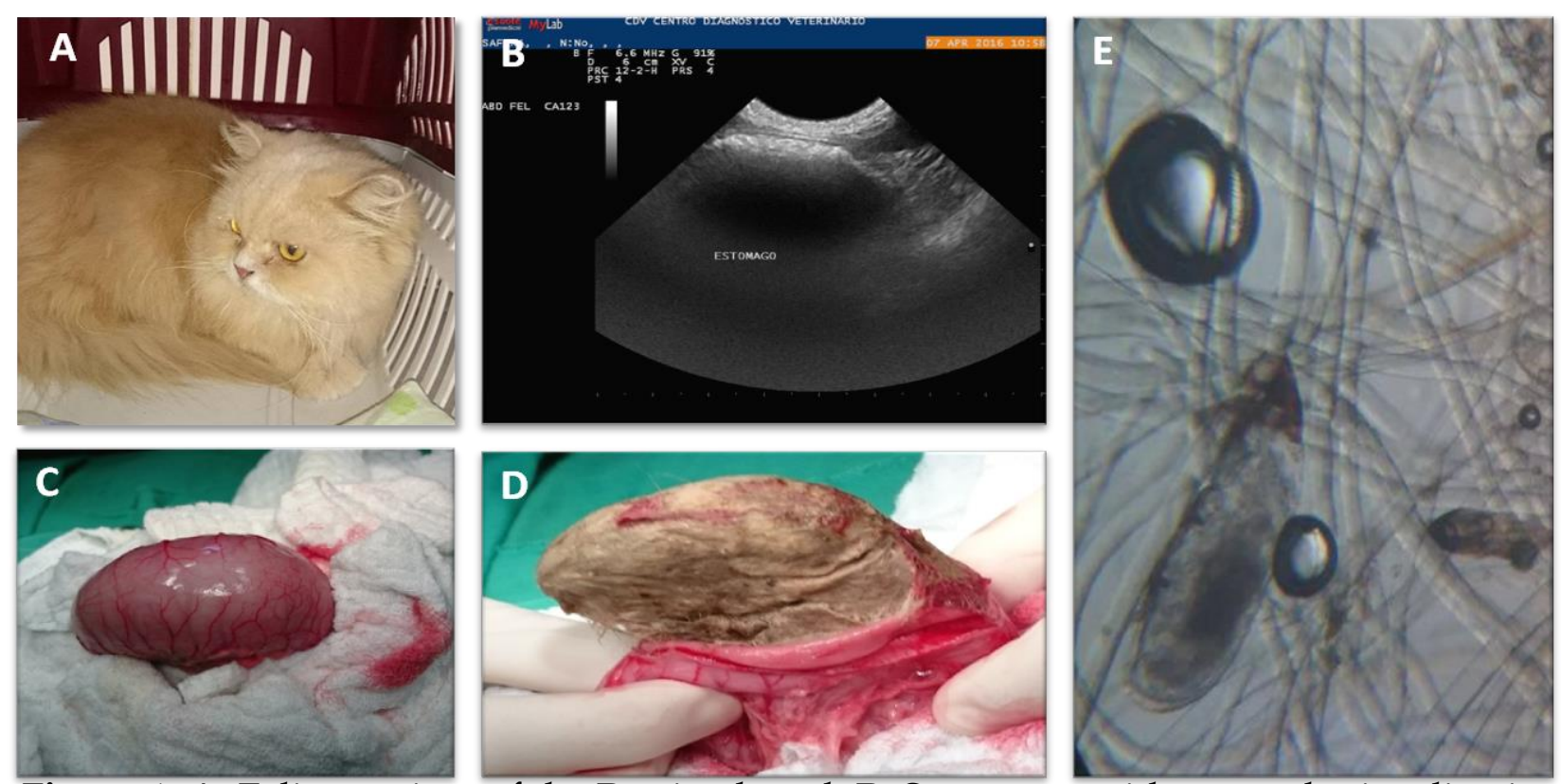

Figure 1. A. Feline patient of the Persian breed. B. Sonogram with stomach visualization with formation of large posterior acoustic shadow. C. Stomach of the feline patient with a large internal mass. D. Withdrawal of the trichobezoar from the feline patient's stomach. E. Visualization of the Lynxacarus radovskyi mite by shaving the feline patient's skin.

\section{Discussion and Conclusion}

Clinical signs such as intermittent vomiting, regurgitation, occasionally associated with abdominal pain, dehydration, partial or complete lack of appetite, skin pruritus dermatitis, flea infestation and/or mite identified in the feline patient presented in this case report consist of factors that contribute to the formation of trichobezoar and that should not be neglected [7-8].

The findings in the anamnesis and physical exams are in accordance with the literature, thus it is possible to suspect trichobezoar, since the Persian cat has a predisposition and the behavior of excessive licking has been reported [4]. 
In the clinical case evaluated, it was found that the diagnosis could not be defined only with complementary exams, so an exploratory laparotomy was requested, since the animal had a large gastric dilation and acoustic shadow production and this parameter according to literature is consistent with the case of bezoars [9].

The conclusion of the diagnosis of trichobezoar based on the presence of the mite Lynxacarus radovsky, was obtained due to the fact that in some animals the infestation by the mite is associated with chronic and debilitating disease or gastrointestinal disorders due to excessive licking and vomiting, constipation, irritation may occur or rectal prolapse and hairballs [5].

As for the therapeutic approach for eliminating the mite, it is based on the fact that the composition of Reolution or Advocte contains Selamectin, an efficient medication for antiparasitic therapy that, when applied in two moments with the interval of one month, guarantees the total elimination of parasites [10].

In this premise, knowing that the ingestion of hairball in cats is something very common, it is necessary that veterinarians should be aware of this excess of cat licking, as they may come to form the trichobezoar, mainly associated pruritic dermatitis, as well as in the presence of the mite Lynxacarus radovskyi, since it causes an intense itching to animals.
Trichobezoar should be used as a differential diagnosis of gastrointestinal obstructions in cats, since it is an emergency procedure, requiring a surgical procedure, because if not treated in time, it can lead to death. It is of utmost importance that the veterinarian identifies the primary cause of the increased frequency of licking to prevent relapses.

\section{References}

[1] Conselho Federal de Medicina Veterinária. População de gatos cresce em média $8 \%$ ao ano no Brasil e está perto de se igualar a de cães. Brasília, 2014.

[2] Pascoal IC, Souza-Neto OL, Silva DJ, Bandeira JT, Silva MBG, Barros RB, Oliveira AAF. Obstrução gástrica por corpo estranho de natureza plástica em felino: relato de caso. Recife: Universidade Federal Rural de Pernambuco, 2013.

[3] Anjos TM. Tricobezoares em felinos. Revista veterinária, 2012.

[4] Farias LF, Silva SL, Souza HJM. Tricobezoar intestinal recorrente associado à tricotilomania em gato. Revista de Educação Continuada em Medicina Veterinária e Zootecnia do CRMV-SP. 2016, 13(3):89-89.

[5] Jaffé E, Grillo S, Costa CLA, Vaz CES, Alves LC, Almosny NRP. Infestação por Lynxacarus radovskyi em cães e gatos domésticos na cidade de Niterói (RJ): relato de caso. Rio de Janeiro: Revista Brasileira de Ciências Veterinárias. 2005, 12(1/3). 
[6] Greve JH, Gerrish RR. Fur mite Lynxacarus from cats in Flórida. Feline Practice, v.11, n. 6, p. 28-30, 1981.

[7] Cannon M. Hair balls in cats: a normal nuisance or a sign that something is wrong? Reino Unido: Oxford Cat Clinic - J Feline Med Surg, 2013.

[8] Beynen AC, Middelkoop J, Saris DHJ. Clinical Signs of Hairballs in Cats Fed a Diet enriched with cellulose. American Journal of Animal and Veterinary Sciences 6, 2011.

[9] Balthazar G, Barella SM, Andrade TCM, Almeida DB, Francisco MC, Reibscheid S, Colleone Neto R, Szejnfeld J. Achados radiográficos no bezoar. São Paulo: Escola Paulista de Medicina. Radiol Bras., 2007.

[10] Silva TIB, Menezes TM, Silva FLM, Fernandes ACC, Müller PM, Silva DD. Obstrução Gastroentérica por Tricobezoários em Felino: Relato de Caso. Recife: IX Jornada de ensino, pesquisa e extensão - JEPEX, 2009.

Conflict of interest: The author declares no conflicts of interest.

Acknowledgements: None.

Funding: None.

How to cite this article: Arruda EN, Marques MS, Galera PD, Sousa-Filho RP, Monteiro CLB. Gastric Obstruction by Tricobezoar in Cat Associated wih Lynxacarus radovskyi: a case report. Brazilian Journal of Case Reports. 2021Abr-Jun;01(2):26-31. 